\title{
LA CONCEPCIÓN DEL DERECHO EN LA OBRA DE MAQUIAVELO
}

Nicolás Maquiavelo es ampliamente conocido como pensador político, incluso es reconocido como el fundador de la teoría política moderna. ${ }^{1}$ Por esta razón la cantidad de escritos acerca de sus concepciones del Estado, de la política, de la guerra y de la historia son muy numerosos. Sin embargo, y a pesar de la estrecha relación que existe entre el derecho y la política, es relativamente poca la literatura que puede encontrarse respecto a la concepción del derecho en Maquiavelo y a la influencia que pudiera haber tenido en el pensamiento jurídico. La explicación de este hecho es desde luego la carencia que existe en la obra de Maquiavelo de un tratamiento sistemático acerca del derecho y, menos aún, de la jurisprudencia. Las referencias al derecho que pueden encontrarse son casi todas incidentales, dado que Maquiavelo está fundamentalmente preocupado, obsesionado podríamos decir, por el arte de la política.

No obstante lo anterior, parece posible ordenar de algún modo las observaciones de Maquiavelo para presentarlas de manera sistemática. Además, puede intentarse inferir, con mayor o menor fidelidad, la concepción del derecho que subyace en el pensamiento del Secretario Florentino. ${ }^{2}$ En este trabajo se abordarán estas cuestiones teniendo a la vista exclusivamente sus obras políticas básicas: El principe y Los discursos sobre la primera década de Tito Livio. ${ }^{3}$

\section{Naturaleza del derecho}

Como una primera aclaración conceptual habría que señalar que bajo el término "derecho" se entenderá aquí lo que Maquiavelo llama leyes, constituciones, sentencias y tratados. Aunque posteriormente nos ocupemos de cada una de estas especies, parece conveniente dar algunas características generales de las mismas. Aun sin decirlo expresamente, en Maquiavelo se encuentran pasajes que indican que pensaba que se trataba de reglas de conducta obligatorias, normalmente dictadas por una autoridad y respaldadas

1 En este sentido véase H. Coing, Grundzüge der Rechtsphilosophie, Gruyter, Berlín, 1969, pp. 28 ss.; G. Sabine, Historia de la teoria politica, FCE, México, 1972, p. 269; y sobre todo, J. Plamenatz, Man and Society, vol. I, Longman, 1963, pp. 4 y 43.

2 Acertadamente señala Plamenatz que Maquiavelo no se pregunta, como los pensadores políticos medievales o griegos, ¿qué es el Estado?, ¿qué es el derecho? Para saber qué entendía por estas palabras hay que ver cómo las usa. Op. cit., p. 17.

3 Nicolás Maquiavelo, Obras politicas, Ed. Poseidón, Buenos Aires, 1943. 
por un castigo para el caso de su incumplimiento. En I, 1, señala, al hablar de los peligros de la holganza, que "debe procurarse que las leyes obliguen al trabajo" y más adelante, "que las leyes de Rómulo, Numa y otros obligaron a severas costumbres". " En el siguiente capitulo habla de que los hombres "acudieron a hacer leyes y ordenar castigos para quienes las infringieran". Más adelante escribe que "los castigos ordinarios no se imputan a los que mandan, sino a las leyes y a las exigencias del orden" (III, 22). No escapaba a Maquiavelo que el derecho podía, obviamente, prohibir también algunas conductas y advierte que la constitución o las leyes de una república pueden prohibir de modo terminante las conquistas $(I, 6)$ o nos recuerda la nefasta práctica de los señores de la Romaña que "hacían leyes prohibiendo cualquier cosa" (III, 29). Pero su visión del derecho no se limitaba al aspecto negativo - ordenar o prohibir - o sancionador del mismo. Con toda claridad apunta que el derecho puede también conceder facultades y constituir por lo tanto órganos jurídicos. En los capítulos 7 y 8 del Discurso Primero recomienda que los funcionarios nombrados en la ciudad como guardianes de su libertad tengan "la facultad de acusar ante el pueblo o ante un magistrado o consejo a los ciudadanos que de algún modo infringen las libertades públicas" (I, 7), insistiendo después en la necesidad de que en una república el legislador establezca "que todo ciudadano pueda acusar a los demás sin temor ni consideración alguna" (I, 8). Conectada con esta noción de facultad aparece en Maquiavelo la noción de la responsabilidad. Al hablar de la institución del decenvirato señala que si el pueblo confiere facultades a un órgano sin establecer medios de hacer efectiva la responsabilidad para el caso de abuso, se crea un poder arbitrario $(I, 40)$. Más adelante se verá cómo podría plantearse la relación entre derecho y poder arbitrario, pero por ahora habría que destacar un último aspecto de las posibilidades que tiene el derecho para regular la conducta. Intimamente ligada con la noción de la facultad está, como ya vimos, la noción del órgano. El derecho, en los textos del autor italiano, organiza al Estado mismo. Los primitivos habitantes de Venecia, refugiados allí de las invasiones de los bárbaros, "comenzaron a regirse por las leyes que juzgaban más a propósito para organizar el Estado" (I, 1). Idea que queda aclarada más adelante al decir que un legislador puede organizar al Estado en una de las tres formas tradicionales de gobierno -monarquía, aristocracia y democracia ( $I, 2)$.

Se dijo anteriormente que todas estas reglas eran dictadas normalmente por la autoridad, esto es, por un órgano facultado por la ley. En efecto, para Maquiavelo la situación normal y deseable era, como señalamos, aquella en la cual existían "medios legales de manifestación de la animosidad de la

4 Las citas se refieren todas, salvo mención en contrario, a la edición de la nota anterior. El número romano indica el número del libro de los Discursos y la siguiente cifra, en arábigo, el capítulo. Los números arábigos precedidos por una $P$, se refieren a los capítulos de El principe. 
multitud contra cualquier ciudadano, porque si no existen estos recursos legitimos, se acude a los extralegales, los cuales ocasionan, sin duda, peores resultados que aquéllos", siendo los encargados de aplicar tales leyes "una autoridad legitima que tiene sus límites propios" (I, 7). Es claro que la solución de conflictos deberá estar a cargo de personas constituidas en autoridad que actúen conforme al derecho y no conforme a la voluntad privada $(I, 7)$. En forma desdibujada, pero ya en embrión, está aquí la idea de que el derecho es la voluntad del Estado, o del pueblo, como algo distinto y casi opuesto a la voluntad privada.

En resumen, la concepción del derecho implícita en Maquiavelo es la de un conjunto de reglas dictadas normalmente por una autoridad, las cuales no sólo ordenan y prohiben ciertas conductas, sino que conceden facultades y constituyen órganos, esto es, organizan al Estado. Las sanciones coactivas - castigos - se imputan, no a los sujetos, sino a las normas legales.

La definición anterior nos coloca dentro de la problemática dominante en la época de Maquiavelo, dado que presenta todos los rasgos de una concepción positivista del derecho. La inmensa mayoria, la totalidad podráamos decir, de los juristas de la Edad Media y del Renacimiento sostenían la existencia de un derecho natural, superior al positivo, que no era producto de los hombres sino de Dios. Las discusiones filosóficas se habían centrado en la cuestión de resolver si tal derecho natural era producto de la voluntad o de la razón divinas. ${ }^{5}$ Una parte muy importante de este derecho natural regulaba definitivamente los problemas relativos a la relación de la comunidad con el individuo, o del soberano con el pueblo. ${ }^{6}$

Nuevamente sería inútil tratar de encontrar en Maquiavelo una opinión expresa en estas cuestiones, sin embargo nos parece que es posible exponer las ideas que están implícitas en sus textos, las cuales muestran una actitud, una concepción que tiene importancia destacar precisamente por lo novedosa. Resultará bastante difícil encontrar un tratadista contemporáneo que se ocupe del Estado y de la política sin reconocer ninguna de las bases del derecho natural. Esto no quiere decir, como pretende Gierke, que Maquiavelo haya rehuido "las bases jurídicas de la vida pública", para entregarse casi exclusivamente "a cuestiones prácticas de pura utilidad"." Maquiavelo se ocupa, a su manera, de las bases jurídicas del Estado, pero, desde luego, no del modo en que lo hicieron los jusnaturalistas tradicionales. Una de las ideas básicas originales de Maquiavelo es que en todo Estado existe un poder supremo -el soberano- que rechaza cualquier límite proveniente de un poder exterior

5 H. Welzel, Naturrecht und Materiale Gerechtigkeit, Vandenhoeck y Ruprecht, Gotinga, 1962, pp. 89 ss.; y F. Meinecke La idea de la razón de Estado en la Edad Moderna, Instituto de Estudios Políticos, Madrid, 1959, p. 29.

${ }^{6}$ O. Gierke, Natural Law and the Theory of Society, Cambridge University Press, Cambridge, 1950, pp. 38 y 39 .

7 Ibid., p. 36 , n. 6. 
-el Papa o el Emperador. El Estado no es ya un fragmento de la cristiandad, ni de ninguna otra abstracción supranacional, y tenía, por tanto, pleno derecho a promulgar sus propias leyes. ${ }^{8}$

El hecho de que Maquiavelo no mencione para nada al derecho natural ha hecho creer a algunos autores que sus reglas son simples máximas políticas ajenas a todo jusnaturalismo. ${ }^{9}$ Los hombres, dice al comienzo de sus Discursos, vivían como animales dispersos, pero al entrar en sociedad se dieron cuenta de que lo que dañaba al bien podía repetirse y "acudieron a hacer leyes y ordenar castigos para quienes las infringieran" ( $I, 2)$. Más adelante precisa que el legislador debe suponer al hombre malo y "dispuesto a emplear su malignidad natural siempre que la ocasión se lo permita" (I, 3). La necesidad del derecho surge, pues, de la naturaleza humana que hace indispensable este medio para prevenir y castigar el mal. Las reglas jurídicas surgen, quizá, al acaso y pueden optar por diversas formas de organización del Estado ( $I, 2)$. Sin embargo, no es dejado al acaso el sistema de normas que debe regirlo. Maquiavelo recomienda al legislador el estudio de los sucesos históricos, puesto que ellos "les inducirán a dictar medidas que refrenen rápidamente los apetitos humanos y quiten toda esperanza de impunidad a los que cometan faltas arrastrados por sus pasiones" (I, $4 \bar{z})$. El derecho dehe surgir a partir de la experiencia. Más aún, al comparar Esparta y Atenas con Roma, señala que las primeras "eran belicosas y tenían excelentes leyes; sin embargo, no llegaron a la grandeza de Roma", y esto se debió a que los legisladores romanos imitaron a la naturaleza y se fortalecieron con ello (II, 3). Las buenas leyes imitan a la naturaleza que ofrece así un criterio para evaluarlas. La naturaleza en Maquiavelo, en particular la humana, constituye un supuesto invariable de toda su filosofía. La naturaleza ofrece un criterio para juzgar las acciones humanas, quien sigue su voz no puede ser censurado, escribe Maquiavelo en una carta en la cual justifica una aventura amorosa en medio de graves ocupaciones: "Si esta conducta parece culpable a ojos de algunos censores, yo, por el contrario, la encuentro digna de elogio, pues imitamos a la naturaleza, siempre variada en su marcha: cualquiera que ajuste su conducta a un modelo semejante, no puede incurrir en reproche". ${ }^{10}$ Se ha dicho que en Maquiavelo puede hablarse de un "derecho natural vital". según el cual la impulsividad natural constituye una legitimación verdadera del soberano en forma de "virtud"."1 Como quiera que esto sea, es claro que

8 Véase R. H. S. Crossman, Biografía del Estado moderno, FCE. México, 197o, pp. 35 ss.; J. R. Hale, "Machiavelli and the Self sufficient State", en Political Ideas, ed. por David Thomson, Pelican Books, 1969 , p. 31, y F. H. Hinsley, Sovereignty, C. A. Watts and Co., Londres, 1966, p. 110.

9 Coing, op. cit., pp. 29 ss.

10 Oeuvres Complêtes, por J. Buchon, t. II, París, 1867, p. 660; Meinecke, op. cit., p. 33, n. 13 .

11 E. Wolf, El problema del derecho natural, Ediciones Ariel, Barcelona, 1960, p. 129. 
la concepción que tenía Maquiavelo del derecho lo coloca muchísimo más cerca de la tradición positivista, de la cual puede considerarse un precursor, que de la imperante concepción del jusnaturalismo teológico. En sus escritos el autor de El principe no le quita nunca su carácter de derecho (ley) a ninguna regla positiva, así sea que contradiga los principios de la moral o las máximas de la política extraídas de la observación histórica. (Más adelante veremos cuál era su criterio para enjuiciar a las leyes.) En ningún momento afirma tampoco la existencia de normas jurídicas inmutables que obliguen al soberano. Que estas ideas se desprenden fácilmente de sus textos puede comprobarse acudiendo a las críticas que le dirigieron sus primeros adversarios: Gentillet y Bodino, jusnaturalistas ambos, aun cuando de orientación muy diversa. ${ }^{12}$

En resumen, si bien no está ausente de la concepción maquiavélica del derecho un cierto elemento jusnaturalista, todo lo que omite, lo coloca mucho más cerca de una concepción pragmática y empirista acerca de la naturaleza del derecho. ${ }^{13}$

\section{Función del derecho}

Señalábamos antes que los elementos jusnaturalistas hacían a Maquiavelo concebir el derecho como un instrumento que en última instancia haria buenos a los hombres. ${ }^{14}$ Antes apuntamos también cómo el derecho resolvía conflictos y organizaba al Estado. Pero para comprender más claramente esta función hay que poner al derecho en relación con el poder y la política, elementos esenciales del pensamiento maquiavélico.

Contra lo que a primera vista pudiera parecer, Maquiavelo no identifica el derecho y el poder. Algunas manifestaciones de fuerza reciben calificativos claramente negativos: "violencia", "tumultos y alborotos", "sublevaciones", etc. ${ }^{15}$ Aparte de éstas, existen otras manifestaciones que se distinguen expresamente del poder legal. Recordemos que al hablar de la creación de órganos carentes de medios para hacerlos responsables, asi como de los "poderes constituidos por la voluntad de quien los ejerce y no los que da el pueblo", Maquiavelo los califica como "poder arbitrario" (I, 40). Este poder "ilegal" no siempre es censurable: "porque donde la corrupción es tan grande que no bastan las leyes para contenerla, se necesita la mayor fuerza de una mano real cuyo poder absoluto excesivo ponga freno a las ambiciones y a la

12 Meinecke, op. cit., pp. $5^{2}$ ss.

13 Es indicativo el hecho de que, buscando una palabra para distinguir a Maquiavelo, tanto de los escritores políticos medievales, como de los exponentes del derecho divino de los reyes y del contrato social, Plamenatz reconozca que es tentador llamarlo positivista. op. cit., p. 7 . p. 237 .

14 P. Villari, Maquiavelo. Su vida y su tiempo, Ed. Grijalbo, México-Barcelona, 1965,

$151,2,5,6,18$, etc. 
corrupción de los magnates" (I, 55). Idea que repite en El principe afirmando que cuando no bastan las leyes hay que usar la fuerza (P. 18).

Habría, entonces, manifestaciones de fuerza absolutamente ilegales y contra todo derecho, otras en cambio, aun yendo más allá de las leyes, estarían justificadas en razón de su fin y en este sentido "legitimadas" y, por último, los usos de la fuerza claramente legales. Nuevamente se aprecia aquí la tensión existente en una posición positivista que contiene elementos jusnaturalistas, a la luz de los cuales se justifican algunas manifestaciones de fuerza.

Sin embargo, la relación entre el derecho y el poder tiene otro aspecto muy importante en la concepción política de Maquiavelo. Hemos señalado que las leyes organizaban el Estado, empero las leyes requieren el apoyo de la fuerza. En un famoso pasaje de El principe se advierte al gobernante que las innovaciones por medio de nuevas leyes fracasarán si se carece del apoyo que da la fuerza: "De todo esto nace que todos los profetas armados hayan triunfado y fracasado todos los inermes" (P. 6). El verdadero fundamento del derecho está constituido por la buena organización militar, sin ella no puede haber buenas leyes (III, 31). Pero la visión de Maquiavelo era demasiado penetrante y audaz para considerar que bastaba con buenas leyes y buenos ejércitos para mantener al Estado, aunque así parezca decirlo en $E l$ principe (P. 24). En los Discursos, sin cuya lectura no puede comprenderse cabalmente el pensamiento de Maquiavelo, ni advertirse muchos de sus atisbos geniales, nos hace saber que las leyes no bastaron para mantener a Roma. La religión es indispensable porque habitúa a la obediencia y mantiene el orden social, siendo más fuerte que la ley para mandar a los ejércitos, reunir al pueblo, y otras empresas comunes. El temor a la religión da mayor estabilidad que el temor al príncipe, a las leyes o a los ejércitos. En el capítulo XI de los Discursos y en los cuatro siguientes, Maquiavelo destaca el papel de lo que hoy llamaríamos la ideología al analizar la función social y política de la religión. El derecho, el poder y la ideología constituyen el fundamento tripartita del Estado, y de ellos la ideología es el más importante. Ni el poder nudo, ni mucho menos las simples leyes sin apoyo militar, permiten la creación y la subsistencia del Estado: "si fuera preciso decidir a cuál rey debió más Roma, a Rómulo o a Numa, creo que sería éste el elegido, porque donde hay religión fácilmente se establecen la disciplina militar y los ejércitos, y donde sólo hay ejércitos y no religión, es muy difícil fundar ésta". ${ }^{16}$ Esta genial idea no había de perderse, aunque sí tuvo que esperar muchos años para ser desarrollada. En Rousseau encontramos un

16 I, 11 debe leerse junto con P. 12. "Las principales bases de todos los Estados... son las buenas leyes y los buenos ejércitos; y como no puede haber buenas leyes donde no haya buenos ejércitos, y donde éstos existen aquéllas también, no hablaré ahora de leyes, sino de las tropas." 
eco muy claro de la misma cuando en las Consideraciones sobre el gobierno de Polonia afirma que Numa, con sus ritos y ceremonias religiosas es el verdadero fundador de Roma. ${ }^{17}$

Caracterizado el derecho como uno de los fundamentos del Estado, queda convertido inmediatamente en un instrumento político, esto es, un medio para la adquisición, conservación y aumento del poder. Con esto quedamos situados en el centro de la problemática del escritor florentino: la técnica política, el arte de gobernar. ¿De qué manera se conectan el derecho y la política?

Si definimos la legalidad como la observancia de la ley o el sometimiento al derecho, encontraremos que en toda la obra está considerada como un instrumento importantísimo para la conservación y aumento del poder. Todos, en opinión de Maquiavelo, deben someterse a la ley. No escatima elogios para lo que llama "estricta observancia de las leyes" (I, 55), insistiendo a lo largo de su obra en que no sólo el pueblo, sino también el rey, el príncipe y los generales se someten a las leyes; ${ }^{18}$ incluso una institución extraordinaria como lo es la dictadura no perjudica al Estado si ha sido creada y concebida "conforme a las leyes" (I, 34). Esta legalidad se extiende a las relaciones internacionales y Maquiavelo no vacila en censurar a los romanos porque "dejaron de castigar a los tres Fabios que, faltando al derecho de gentes, combatieron contra los galos" (III, 1), reproche que dirige también a Savonarola, porque en Florencia dejó de cumplir una ley que establecía la apelación al pueblo en caso de sentencias por delitos políticos. Este mal ejemplo es calificado de "peligrosísimo para los que gobiernan un Estado" (I, 45). "Sepan los príncipes, dice más adelante, que empiezan a perder el trono cuando comienzan a quebrantar las leyes y los antiguos usos y costumbres" (III, 5).

Estrechamente vinculado con esta situación aparece aquel estado que Maquiavelo denomina "corrupción", uno de los conceptos clave de sus Discursos. En ella existe una ineficacia patente de las leyes (III, 1 y 28), se destruyen los fundamentos mismos del Estado "porque ni se practica la religión, ni se cumplen las leyes, ni se observa la ordenanza militar". ${ }^{19}$ Este estado de cosas está vinculado al dominio de la clase feudal "que vive ociosamente de las rentas de sus numerosas posesiones, sin cuidarse para nada de cultivarlas ni tener ninguna otra ocupación o profesión de las necesarias para la vida" (I, 55); estos ricos pueden fácilmente violar la ley y corromper a los demás con sus riquezas, ${ }^{20}$ y representan el triunfo de la ambición individual y la tiranía frente al Estado (III, 22). Al concepto de "corrupción" se opone

17 En Rousseau la "religión civil" funciona también como ideologfa.

18 I, $9,16,5^{8}$ y P. 12.

19 II, Prólogo.

20 I, 24 y III, 16. 
el de "libertad" (I, 49 y 55), pero claro está que para Maquiavelo ésta significa libertad del Estado, no de los individuos, frente a los ricos y posibles tiranos (III, 28). Es explicable que en el siglo xv un tebrico político estuviese más preocupado por defender al Estado frente a ciertos ciudadanos que al revés, sobre todo si este teórico era italiano y por añadidura florentino. La libertad se presenta así como un equilibrio conseguido mediante la ley entre nobles y pueblo $(I, 46)$, y precisamente por ello se dice en otro lugar que las leyes en favor de la libertad nacen del desacuerdo entre nobles y pueblo $(I, 4)$. En esta conciliación de los intereses de clase ve Maquiavelo el bien común. Es falso que no se haya ocupado de él; ${ }^{21}$ lo hace, pero no del modo en que lo trataba la escolástica y varias veces habla de las buenas leyes refiriéndose a ellas como a las que buscan el bien común y no la ambición personal. ${ }^{22}$

La legalidad es así un instrumento para conservar el poder político, para mantener al Estado $(I, 7)$ o para afianzar al príncipe, como dice en otra parte (P. 8), ya que por ella se consigue la obediencia (III, 22). Las leyes son el instrumento para prever los peligros que amenazan al Estado (I, 34), aunque la historia enseña "lo difícil que es proveerlo de todas las İeyes necesarias para mantener ia iỉbertad" (i, 49). La lèy, pơr úlíñó, pếmite aumentar el poder en el ámbito internacional como medio de conquista, nos dice el discípulo citando a su maestro Tito Livio "quod jam non solum sed jura romana pollebant" (II, 21).

Esta actitud de Maquiavelo frente a la legalidad ha sido señalada ya, en términos más o menos generales, por varios autores. ${ }^{23}$ Empero, vale la pena hacer notar que no señalan el silencio o por lo menos el escaso énfasis que pone Maquiavelo sobre la legalidad y la corrupción en El principe.

\section{Teoria de la legislación}

Es incuestionable que la figura del legislador ocupa un lugar central en la visión que tenía Maquiavelo del Estado. ${ }^{24}$ El legislador es el fundador del Estado y su primer gobernante. Rómulo, Licurgo, Solón, son los ejemplos más socorridos y más ilustres. Algunos autores modernos han equiparado la figura antigua del legislador maquiavélico con la del líder moderno..25

p. 284

21 J. Corts Grau, Historia de la filosofia del derecho, Editora Nacional, Madrid, 1960,

22 I, 9; II, 2 y III, 3 .

23 Sabine, op. cit., p. 261 y sobre todo E. Namer, Machiavel, PUF, Paris, 1961, p. $3^{8}$ y 136. La opinión de Meinecke coincide en principio aun cuando después confunde derecho y moral, op. cit., pp. 46 y 52 .

24 Como lo tendría también en Rousseau. Véase Considérations sur le gouvernement de Pologne, cap. II.

25 M. Lerner, Machiavelli. Cynic, Patriot or Political Scientist, colección de ensayos 
Sin profundizar en esta interpretación ayudada quizá por algunas traducciones no exentas de extrapolación, ${ }^{26}$ diremos que tal figura dista mucho del filósofo platónico y parecería mejor concebida en los términos de un político o estadista. Este individuo, puesto que Maquiavelo descalifica expresamente al pueblo para esta tarea (I, 58 ), encargado de organizar políticamente al Estado en una forma de gobierno, procede de un modo pragmático. Su virtud se manifiesta en su habilidad y prudencia para escoger el sitio y la naturaleza de las leyes que han de regir $(I, 1)$. Atinadamente escribe Villari que Maquiavelo creyó haber descubierto que todos los grandes eventos políticos eran invariablemente producto de la voluntad e inteligencia osada de grandes hombres. ${ }^{27}$

Como consecuencia de lo anterior, la legislación es contemplada por Maquiavelo como una actividad política, como política legislativa, y en este sentido se fundamentaría más en la ciencia política que en la filosofía o en la axiología. El método de proceder es el histórico-inductivo que subyace en toda la obra de Maquiavelo. Para dictar las medidas convenientes el legislador ha de estudiar los sucesos históricos (I, 42). A este respecto, las observaciones que nos trasmite el autor son escasas y dispersas. Como buen republicano es partidario del sistema popular de elección para los cargos públicos ya que afirma "que los pueblos escogen mejor que los príncipes" (III, 34). Igualmente recomienda la implantación de recursos legales para que el órgano pueda controlar a otro ( $\mathrm{I}, 5 \mathrm{o})$, así como no prolongar la duración del ejercicio de los cargos civiles y militares (III, 24). Otra sugerencia, que recuerda por cierto a Platón, ${ }^{28}$ señala la conveniencia de que los tribunales populares estén integrados por numerosos ciudadanos, de modo que se evite la presión y el cohecho de los ciudadanos influyentes $(I, 49)$. No es necesario insistir en que los criterios para calificar a las leyes como buenas son, pues, primordialmente políticos. El valor supremo es el bien común o bien del Estado. Es en los Discursos en donde pueden leerse "cuando hay que resolver acerca de su salvación (de la patria), no cabe detenerse por consideraciones de justicia o de injusticia, de humanidad o de crueldad, de gloria o de ignominia. Ante todo y sobre todo, lo indispensable es salvar su existencia y su libertad" (III, 41).

La legislación tenía, empero, un límite que Maquiavelo señaló varias veces. Una vez corrompido el pueblo ya ni siquiera las mejores leyes aplica-

publicados bajo el título "Problems in European Civilization", por De Lamar Jensen, Heath and Company, Boston, 1965, p. 10.

26 En el capitulo 24 de El principe, se dice, en la edición en español, que el nuevo principe dará buenos ejenrplos y, en la traducción inglesa de George Bull - Penguin Classics- de 1961 se habla de "inspiring leadership".

27 Villari en "Machiavelli. Cynic, Patriot or Political Scientist", p. 19.

28 H. Cairns, Legal Philosophy from Plato to Hegel, Johns Hopkins Press, Baltimore, 1967 , p. 10. 
das con severidad podrán salvarlo de la anarquía y la decadencia (I, 17). En esas condiciones el instrumento legal es políticamente inútil, resultando "dificilisimo restablecer el imperio de las leyes" (III, 28). La explicación que se ofrece es la dependencia mutua que existe entre las buenas leyes y las buenas costumbres (I, 18), incluso en ocasiones éstas pueden lograr efectos positivos sin necesidad de aquéllas (III, 25).

\section{Teoria de la Constitución}

Dentro de la legislación existe una norma particularmente importante desde el punto de vista político, pues ella más que ninguna otra organiza el Estado: la Constitución. En Maquiavelo se encuentran algunas reflexiones sobre ella, concentradas en los Discursos. Al comienzo de éstos apunta una clasificación: aquellas que, hechas sabiamente, permiten vivir con seguridad sin necesidad de ser corregidas y las que teniendo buenos principios son perfectibles (I, 2). Al hablar de la Constitución de Roma escribe: "Para que se entienda mejor, diré cuál era en Roma la organización del gobierno o del Fstado y cúles las leyes que, con los magistrados, refrenaban a los ciudadanos. Las bases de la Constitución eran la autoridad del pueblo, del senado, de los tribunos y de los cónsules; el sistema de elección y nombramientos de los magistrados y la forma de hacer leyes." Las leyes eran la del adulterio, las suntuarias, la de soborno, la ley agraria, etc. (I, 18). Se ve cómo la norma fundamental del sistema jurídico establece los órganos supremos, así como los procedimientos básicos de creación de las otras leyes. La Constitución, continúa el capítulo, "varió poco o nada, a pesar de tantos y tan diversos acontecimientos. Cambiaron las leyes que refrenaban a los ciudadanos". Las leyes derivadas de la Constitución no tienen ya una función organizadora propiamente sino refrenadora, son las normas típicamente coactivas. Pueden distinguirse, además, por la facilidad de su reforma. Líneas antes dice el autor: "Las leyes cambian con arreglo a las circunstancias y a los sucesos; pero no varía, o rara vez sucede que varíe la Constitución, lo que ocasiona que las nuevas leyes sean ineficaces por no ajustarse a la Constitución primitiva o contrariarla." Además de su reformabilidad, común en un caso y extraordinaria en el otro, Maquiavelo indica la necesidad de mantenerlas congruentes. En este mismo capítulo habla de la necesidad que hubo en Roma de reformar la Constitución y de los modos de hacerlo: "Cuando se comprende que la Constitución de un Estado no es buena, se cambia de pronto o se reforma poco a poco, a medida que se van conociendo sus defectos; pero ambos métodos son casi irrealizables." Aquí, y en otros lugares, Maquiavelo califica de peligrosos los intentos de su reforma (I, 2). La necesidad de su cambio debe ser evidente al pueblo, como fue el caso de Roma en que se constituyeron abusos perniciosos en la práctica de la elección de 
los órganos por defectos del sistema electoral. Igualmente el procedimiento de iniciativa y discusión de leyes que correspondía originalmente a cualquier ciudadano, había sido viciado en favor de los poderosos y ponía en peligro la libertad (I, 18).

Dos ideas más se encuentran sobre la Constitución. La primera es la famosa tesis de la división de poderes, entendida aquí como la combinación de las tres formas de gobierno. Una buena Constitución establece un régimen mixto, "el cual será más firme y estable; porque en una constitución donde coexisten la monarquía, la aristocracia y la democracia, cada uno de estos poderes vigila y contrarresta los abusos de los otros" (I, 2; el subrayado es nuestro). Ciertamente no era original en ello, sino que más bien se inscribía en la larga tradición clásica, influido seguramente por Polibio o por Cicerón..$^{29}$ La segunda, estrechamente conectada con la legalidad, se refiere a los efectos nocivos que tiene violar la Constitución, aun para hacer el bien, pues ello "conduciría a quebrantarla con tal pretexto, para, en realidad, hacer el mal" (I, 34).

\section{Derecho internacional}

Principalmente en el libro II, dedicado a discurrir sobre lo que hicieron los romanos para ensanchar su dominación, se encuentran algunas observaciones respecto al derecho internacional (ius gentium), todas ellas dentro del estilo maquiavélico.

Nunca son tachados los tratados internacionales de ilicitos o de nulos. Aun aquellos que son "durísimos" (II, 6) o impuestos por la fuerza. Claro está que advierte que estos últimos no serán fielmente cumplidos, como tampoco lo serán los que ponen en peligro al Estado (I, 59). De pasada señala que pueden romperse también por inobservancia de alguna de las cláusulas, pero le interesa más el caso de las razones políticas para la violación. Si han de respetarse los tratados de paz y de alianza es por razones políticas, pero las naciones poderosas cuentan con multitud de estratagemas para violarlas (II, 9). Cuando esto no es políticamente conveniente, Maquiavelo se apresura a censurar la violación de los embajadores romanos (II, 28; III, 1). El criterio moral se asoma en el capítulo 42 (III) titulado "Las promesas hechas por fuerza no deben ser cumplidas", el cual se refiere al conflicto entre los samnitas y los romanos. La tensión entre el positivismo radical y los vestigios jusnaturalistas vuelve a mostrarse.

La guerra, uno de lo temas favoritos de Maquiavelo, recibe el mismo tratamiento. No se opone ni a la conquista, ni a la destrucción de un Estado, ya que políticamente son ventajosas (II, 8), y al efecto es curioso notar que la

29 R. Zippelius, Allgemeine Staatslehre, C. H. Beck, Munich, 1971, pp. 65, 133. 
última cita de Livio en el famoso capítulo XXVI de El principe señala que "hay una gran justicia en nuestra causa: iustum enim est bellum quibus necessarium, et pia arma ubi nulla nisi in armis spes est". ${ }^{30}$

\section{Justicia}

Tradicionalmente, la justicia ha sido un criterio para enjuiciar las acciones, particularmente los actos legales. En este sentido es un criterio situado por encima del derecho, en el orden de la moral y de la ideología. Las tesis del positivismo radical niegan toda posibilidad de un conocimiento objetivo de la justicia y afirman que la única justicia que puede afirmarse objetivamente es la llamada "justicia legal". Lo justo es entonces lo que es conforme a la ley positiva. ${ }^{31}$

La tensión del pensamiento maquiavélico se manifiesta al distinguir la legalidad de la justicia, cuando afirma que "si un ciudadano es oprimido, aunque lo sea injustamente, pero dentro de la legalidad, escaso o ningún desorden acontece, pues la opresión no es producto de violencia privada ni de fuerza extranjera, que son las que acaban con la libertad, sino del cumplimiento de las leyes realizado por una autoridad legítima" (I, 7). Existe, pues, la posibilidad de la injusticia legal; la justicia es un criterio más allá del derecho aunque, como dice el propio Maquiavelo, con el nacimiento del derecho nació el conocimiento de la justicia (I, 1). Sin embargo, la injusticia queda, por decirlo así, "justificada" cuando se comete en bien del Estado o de la Patria; no hay que olvidar que salvarla está por encima de la justicia y de la dignidad (III, 41). En cambio, la injusticia que causa "grandes males en la república" es reprobable. El no reconocer los méritos de los grandes hombres en épocas tranquilas es un "mal" que hay que evitar con medidas políticas (III, 16).

La subordinación de la justicia a la política se advierte también en la aplicación de la ley a los ciudadanos que han obrado mal. En una primera parte se dice que habrá que castigarlos "sin consideración alguna a sus precedentes servicios", ya que de hacerlo, "puede gozar una república de libertad largo tiempo: de otra suerte camina a pronta ruina" (I, 24). Este severo principio contrasta con el consejo dado siete capítulos más adelante en relación con el castigo a los generales romanos. Con ellos la república fue "menos severa y más parca, si éstos erraban por malicia los castigaba humanamente, y si por ignorancia, en vez de imponerles penas, les daba premios y

30 Véase edición inglesa, Penguin Classics.

31 Aunque Maquiavelo coincida con Hobbes en que la justicia es efecto del derecho $(I, 2)$, no es exacto que coincida con él en que el derecho positivo es el único criterio de lo justo y lo injusto. Esta observación es hecha por Plamenatz (op. cit., p. 28), quien añade que no hay evidencia de que Maquiavelo acepte la segunda tesis. En el texto creemos probar que incluso hay evidencia de que distingue lo justo de lo legal (I, 7). 
honores" (I, 31). Para mayor claridad de esta subordinación de valores a la política, mencionamos el caso de Tito Manlio, narrado más adelante (III, 34). Este "hizo matar a su hijo por haber combatido sin orden suya, aunque venció al enemigo". Actos como éste, continúa Maquiavelo, "han perpetuado su nombre a través de los siglos". La admiración de Maquiavelo no deja de ser escalofriante. Cuando Namer, al hablar de la concepción de la justicia de Maquiavelo, señala que responde a una aspiración histórica de los hombres que es la justicia terrestre, legalmente definida, a la que todos los individuos tienen derecho y a la que deben concurrir de grado o por fuerza por ser el medio más favorable a la virtud ${ }_{{ }^{32}}$ nos parece que hace una presentación demasiado simplista del pensamiento maquiavélico.

\section{Conclusión}

La exposición anterior es una pretensión de sistematizar una concepción que se encuentra dispersa e imprecisa a lo largo de la obra de Maquiavelo. En consecuencia adolece de los defectos de todo esfuerzo de esta índole. Por una parte la exactitud de la interpretación ha sido sacrificada en aras de la fidelidad a los textos del autor. Por otra, la interpretación ha destacado ciertos puntos de la concepción maquiavélica del derecho, descuidando u omitiendo otros.

A pesar de ello no parece exagerado ver en Maquiavelo un precursor del positivismo jurídico. Así como su actitud frente al Estado era la de estudiarlo tal y como era, ese mismo espíritu aparece en sus comentarios acerca del derecho. Nada más alejado de él que concebirlo como un orden metafísico y trascendente vinculado con la divinidad o con una doctrina filosófica. El derecho era, para Maquiavelo, el derecho existente entre los hombres y entre los Estados. Su preocupación era la manera de utilizarlo con fines políticos. A pesar de su pragmatismo y realismo no logró superar la tensión entre describir simplemente lo que era y recomendar lo que debería hacerse. El derecho debía servir para el bien del Estado y tanto la república romana como la naturaleza eran dos modelos que lo guiaban en su búsqueda del bien público.

Pero lo anterior no es un reproche a Maquiavelo. Nos parece que el fruto de ese conflicto consiste a menudo en ideas esclarecedoras que guían por muchos siglos al pensamiento.

INSTTTUTO DE INVESTIGAGiones FiLOSÓficas

JAVIER ESQUIVEL.

Universidad Nactonal Autónoma de México

32 Namer, op. cit., p. 231. 